\title{
Structure design of the drill stem of the hand-held excavator
}

\author{
Zhenhui Luan ${ }^{\mathrm{a}}$, Shan Wang ${ }^{\mathrm{b}}$ \\ Mechanical Engineering school, Anhui University of Science and Technology, Huainan, Anhui, \\ 232001, China

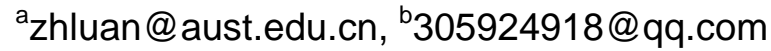

Keywords: drill stem, pneumatic conveying, structure design, hand-held excavator

\begin{abstract}
The hand-held excavator was particularly designed for artificial excatating pile drilling. It consisted of a motor, a gear reducer, a drill stem, a frame and a drill bit. The drill stem was an important component of the hand-held excavator. In order to improve the drilling speed of the excavator, the structure of the drill stem was designed, besides, the forces on the leaf blade, the pressure losss and the best conveying speed of the pneumatic conveying and so on were calculated, and the fan was selected. The research indicates that the drill stem can suitable for the hand-held excavator.
\end{abstract}

\section{Introduction}

Artificial excavating pile has the advantages of convenient construction, saving investment, high speed and large capacity etc, it is widely used in the highway, railway, construction, power transmission project (tower) ${ }^{[1,2]}$. However, the Artificial excavating pile also has the disadvantages, for example, the construction method of artificial excavating pile is manually from top to bottom layer with a pick and shovel and other tools, when meet with the hard soil layer, using a hammer and drill rod to broke, the waste soil is loaded by the bucket, and lift vertically from the wellhead by human gallows or small hoist. Manual excavation is slow, low efficiency, large labor intensity and poor safety.

In view of the present situation, the authors particularly designed the hand-held excavator ${ }^{[3]}$, it had the advantages of simple structure, light weight, small volume, more convenient to carry, and so on. It can be operated by one person, and has high efficiency of excavation.

The drill stem is the key part of the hand-held excavator, it's structure will impact directly on the performance of the excavator.

\section{The working principle of the hand-held excavator}

As shown in Fig.1, the hand-held excavator is comprised of a motor (1), a gear reducer (2), a frame (3), a drill stem (5), and a cylinder (10) and so on. In the middle of the frame (3) there is a transmission shaft (8), which is hollow inside, but its upper ends is closed, and in the middle there is a radial through hole. In the upper part of the frame (3) a reducer (2) is installed, at the top of the reducer (2) a motor (1) is installed, the transmission shaft (8) is driven by the motor (1). A cylinder (10) is installed below the frame (3), there is a hollow drill stem (5) in the middle of the cylinder (10). There is a through hole on the side of the frame (3), an electromagnetic valve (6) is installed in the hole, and the air comed from the fan (7) enteres into the frame (3) through the electromagnetic valve (6). The motor (1) drives the drill stem (5) through the reducer (2), the air enteres into the frame (3) through the hole at the side of the frame (3), and passes the middle hole of the drill stem (5), discharges from the radial holes (9) at the bottom of the drill stem (5). The soil excavated discharges from the outlet (4) in the side wall of the cylinder (10) not only by the helical blade of the stem (5), but also by the pneumatic conveying. 


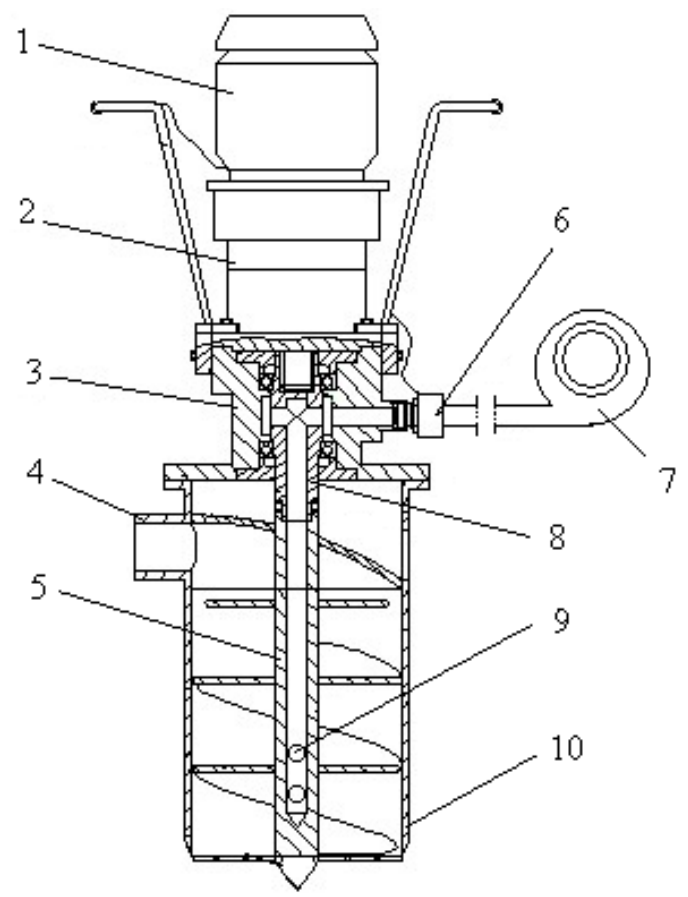

Figure 1. the structure diagram of the hand-held excavator 1.motor, 2.reducer, 3.frame, 4.outlet, 5.drill stem, 6. electromagnetic valve, 7.fan, 8. transmission shaft, 9.hole, 10.cylinder

\section{Structure of the stem}

As shown in Fig.2, the stem is comprised of a drill pipe (11), two cutters (12), two helical blades (13) a drill bit (14) and some cutting teeth (15). The soil excavated by cutting teeth (15) will be improved by the helical blades (13). The cutters (12) are for cutting soil into particales so that they can be discharged outlet smoothly, and the drill bit (14) is for entering soil easily.

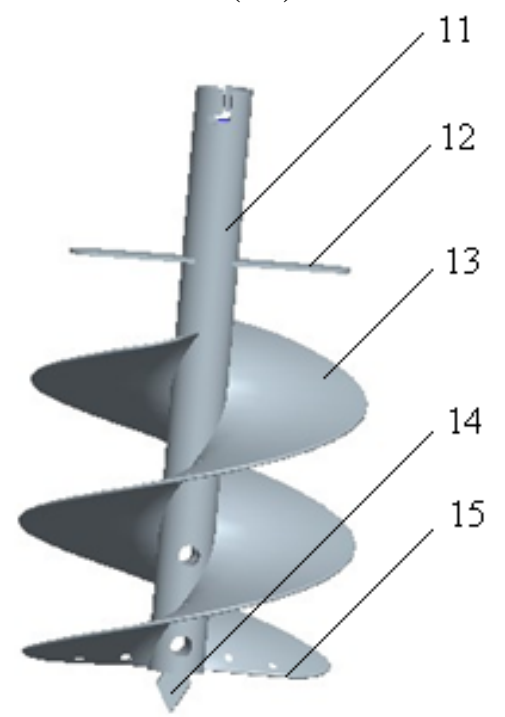

Figure 2. the structure diagram of the stem

11.drill pipe, 12.cutter, 13.helical blade, 14.drill bit, 15.cutting tooth

In order to determine the helix angle of the helical blade of the stem, it is necessary to analyse the forces of soil particles on the helical blade. The centrifugal force of the soil particles is

$$
\mathrm{F}=\frac{1}{4} \mathrm{~m} \omega \mathrm{r}^{2}
$$

where $\mathrm{m}$ is the quality of the soil particles, $\omega$ is the rotation speed of the drill stem, $r$ is the radius of the stem. 
The radial friction is

$\mathrm{f}=\operatorname{mg} \mu \cos \beta$

where $\mathrm{g}$ is the acceleration of gravity, $\mu$ is the coefficient of friction between soil particles and the blade, and $\beta$ is the helix angle.

In order to make the soil particles discharged smoothly, it is necessary to make the centripetal force greater than the radial friction, that is $\mathrm{F}>f$, so

$$
\beta<\arccos \left(\frac{\omega \mathrm{r}^{2}}{4 \mathrm{~g} \mu}\right)
$$

Usually, the digging machine's spiral rise angle is $20^{\circ} \sim 30^{\circ[4]}$, here we determined helix angle of the stem was $25^{\circ}$.

\section{The parameter calculation of pneumatic conveying}

In order to improve the displacement efficiency of the excavator, it equipped with pneumatic system. As shown in Fig.1, the pneumatic system consists of fan (7), electromagnetic valve (6), the frame (3), the transmission shaft (8), the drill stem (5), cylinder (10) and outlet (4). The fan (7) makes air into the stem (5) through electromagnetic valve (6), the frame (3) and the transmission shaft (8). The soil excavated by cutting teeth (15) will be improved by the pneumatic system.

Suspension speed of the soil particles Assuming that the average particle size of the soil particles is $10 \mathrm{~mm}$, the density is $2400 \mathrm{~kg} / \mathrm{m}^{3}$, air density is $1.2 \mathrm{~kg} / \mathrm{m}^{3}$, and viscosity is $\mu=18.2 \times$ $10^{-6} \mathrm{Ns} / \mathrm{m}^{2[5]}$, then

$$
\begin{aligned}
& \left(\frac{\mu^{2}}{\left(\rho_{\mathrm{s}}-\rho\right) \rho}\right)^{1 / 3}=0.486 \times 10^{-4} \\
& \text { so } 20.4\left(\frac{\mu^{2}}{\left(\rho_{\mathrm{s}}-\rho\right) \rho}\right)^{1 / 3}=0.99 \times 10^{-3} \\
& 1100\left(\frac{\mu^{2}}{\left(\rho_{\mathrm{s}}-\rho\right) \rho}\right)^{1 / 3}=53.46 \times 10^{-3} \\
& 20.4\left(\frac{\mu^{2}}{\left(\rho_{\mathrm{s}}-\rho\right) \rho}\right)^{1 / 3} \leq 10 \times 10^{-3} \leq 1100\left(\frac{\mu^{2}}{\left(\rho_{\mathrm{s}}-\rho\right) \rho}\right)^{1 / 3}
\end{aligned}
$$

so the soil particle is at differential pressure resistance area.

Based on Newton formula on the differential resistance area, the suspension speed of the soil particle is as below ${ }^{[6]}$.

$$
\mathrm{V}_{0}=5.45 \sqrt{\frac{\mathrm{d}_{\mathrm{s}}\left(\rho_{\mathrm{s}}-\rho\right)}{\rho}}=5.45 \sqrt{\frac{10 \times 10^{-3}(2400-1.2)}{1.2}}=24.37 \mathrm{~m} / \mathrm{s}
$$

The critical conveying speed According to the suspension speed and the average particle size of the soil particles, the Reynolds number is as below.

$$
\mathrm{R}_{\mathrm{e}}=\frac{\mathrm{Vd}_{\mathrm{s}} \rho}{\mu}=\frac{24.37 \times 10 \times 10^{-3} \times 1.2}{18.2 \times 10^{-6}}=16.1 \times 10^{3}
$$

Selecting cast iron pipe as the material of the cylinder, and its roughness is $E=0.25 \mathrm{~mm}$, and the diameter of the cylinder is $D=240 \mathrm{~mm}$, so the friction coefficient $f_{s}$ between the cylinder and soil particles can be calculated as below ${ }^{[7]}$.

$$
\frac{1}{\sqrt{\mathrm{f}_{\mathrm{s}}}}=-2 \log \left(\frac{\mathrm{E} / \mathrm{D}}{3.89}+\frac{5.58}{\left(16.1 \times 10^{3}\right)^{0.9}}\right)=6
$$

so $\mathrm{f}_{\mathrm{s}}=0.028$.

The friction coefficient $f_{a}$ between the cylinder and air can be calculated as below. 


$$
\mathrm{f}_{\mathrm{a}}=0.0125+\frac{0.0011}{\mathrm{D}}=0.0125+\frac{0.0011}{0.24}=0.017
$$

According to Newton formula on the differential resistance area, the critical conveying speed is below.

$$
\mathrm{V}_{\mathrm{k}}=\left(\frac{2}{3} \sqrt{\mathrm{b}^{2}-3 \mathrm{c}} \cos \frac{\varphi}{3}-\frac{\mathrm{b}}{3}+\mathrm{V}_{0}^{\mathrm{t}}\right)^{1 / \mathrm{t}}
$$

where $\mathrm{t}=1, \mathrm{~b}=2 \mathrm{~V}_{0}=48.74, \mathrm{c}=0$ and $\varphi=\arccos \left(\frac{-1462}{\sqrt{\left(\mathrm{b}^{2}-3 \mathrm{c}\right)^{3}}}\right)$, so $\mathrm{V}_{\mathrm{k}} 34.12 \mathrm{~m} / \mathrm{s}$.

The best conveying speed The best conveying speed of the pneumatic system can be determined by the formula as below.

$$
\mathrm{V}=\alpha \beta \mathrm{V}_{0}
$$

where $\alpha$ is safety factor, and when Reynolds number is at differential pressure resistance area, $\alpha=1 \sim 1.5$, here determining $\alpha=1.007$. And $\beta=0.95$ is a correction coefficient. According to Eq.(13), the best conveying speed is $V=32.6 \mathrm{~m} / \mathrm{s}$.

\section{The air volume calculation}

In pneumatic system, the air volume $\mathrm{Q}$ can be determined by the formula as below.

$$
\mathrm{Q}=\mathrm{kVS}
$$

where $\mathrm{k}$ is additional coefficient, here determining $\mathrm{k}=0.1, \mathrm{~S}$ is cross-sectional area of pipeline.

According to Eq.(14), the air volume is $Q=0.146 \mathrm{~m}^{3} / \mathrm{s}$.

\section{Summary}

The hand-held excavator was designed for artificial excavating piles. In order to discharge soil particles out the cylinder smoothly, the authors not only designed the stem, but also selected the pneumatic system in particular, and calculated the parameters of the pneumatic system. Through the model simulation, the soil particles excavated by the hand-held excavator can be discharged out the cylinder smoothly.

\section{Reference}

[1] Xiao Q B. A brief discussion of the extent of application of artificial excavating pile.Technology Wind, 2011 (04), pp125(In Chinese).

[2] Huang W. Research on the construction technology of artificial excavating pile.Sichuan Building Material, 2012(4), pp144-145(In Chinese).

[3] Zhenhui Luan, Weipeng Gao and Chao Wang. Structure Design of Hand-held Excavator. Applied Mechanics and Materials. Vols.405-408(2013), pp3239-3242.

[4] Qu J X, Liu M G. 3D Modeling and optimization analysis of blades and taper-spiral auger's tip. Forestry Machinery \& Woodworking Equipment, 2009(03), pp39-43(In Chinese).

[5] Yang C X. Design and experimental analysis of test equipment for powder material friction coefficient. Beijing university of chemical, 2012(In Chinese).

[6] Chen Z X. Design handbook for pneumatic conveying powder. The national chemical engineering technology center, 2001(In Chinese).

[7] Li G F. Pipe resistance experiment for dense phase pneumatic conveying. North China electric power university, 2002 (In Chinese). 